Research article

Open Access

\title{
Intact and total insulin-like growth factor-binding protein-3 (IGFBP-3) levels in relation to breast cancer risk factors: a cross-sectional study
}

\author{
Caroline Diorio $1,2,3,4$, Jacques Brisson 2,3,4, Sylvie Bérubé3,4 and Michael Pollak ${ }^{5}$
}

\begin{abstract}
${ }^{1}$ McGill University, Breast Cancer Functional Genomics Group and McGill Centre for Bioinformatics, 3775 University Street, Montreal, QC H3A 2B4, Canada

2Université Laval, Département de médecine sociale et préventive, 2180 Chemin Sainte-Foy, Québec, QC G1K 7P4, Canada

3Unité de recherche en santé des populations, Centre hospitalier affilié universitaire de Québec, 1050 Chemin Sainte-Foy, Québec, QC G1S 4L8, Canada

${ }^{4}$ Centre des maladies du sein Deschênes-Fabia, Centre hospitalier affilié universitaire de Québec, 1050 Chemin Sainte-Foy, Québec, QC G1S 4L8, Canada

${ }^{5}$ Cancer Prevention Research Unit, Lady Davis Institute of the Jewish General Hospital and McGill University, Departments of Medicine and Oncology, 3755 Cote Ste-Catherine Road, Montreal, QC H3T 1E2, Canada
\end{abstract}

Corresponding author: Caroline Diorio, caroline.diorio@uresp.ulaval.ca

Received: 16 Jan 2008 Revisions requested: 6 Feb 2008 Revisions received: 2 May 2008 Accepted: 9 May 2008 Published: 9 May 2008

Breast Cancer Research 2008, 10:R42 (doi:10.1186/bcr2093)

This article is online at: http://breast-cancer-research.com/content/10/3/R42

(c) 2008 Diorio et al.; licensee BioMed Central Ltd.

This is an open access article distributed under the terms of the Creative Commons Attribution License (http://creativecommons.org/licenses/by/2.0), which permits unrestricted use, distribution, and reproduction in any medium, provided the original work is properly cited.

\begin{abstract}
Introduction Levels of insulin-like growth factor (IGF)-I and its main binding protein (IGFBP-3) have been associated with breast cancer risk among premenopausal women. However, associations of IGFBP-3 levels with breast cancer risk have been inconsistent, possibly due to the different predominant forms of circulating IGFBP-3 (intact versus fragmented) that were measured in these studies. Here, we examine the association of breast cancer risk factors with intact and total IGFBP-3 levels.
\end{abstract}

Methods This cross-sectional study includes 737 premenopausal women recruited at screening mammography. Plasma intact and total IGFBP-3 and IGF-I levels were measured by enzyme-linked immunosorbent assay methods. Percent and absolute breast density were estimated using a computer-assisted method. The associations were evaluated using generalized linear models and Pearson $(r)$ or Spearman $\left(r_{s}\right)$ partial correlation coefficients.

Results Means \pm standard deviations of intact and total IGFBP3 levels $(\mathrm{ng} / \mathrm{mL})$ were 1,044 \pm 234 and 4,806 \pm 910 , respectively. Intact and total IGFBP-3 levels were correlated with age and smoking. Levels of intact IGFBP-3 were negatively correlated with waist-to-hip ratio (WHR) $(r=-0.128 ; P=$ $0.0005)$, parity $\left(r_{\mathrm{s}}=-0.078 ; P=0.04\right)$, and alcohol intake $(r=-$ $0.137 ; P=0.0002)$ and positively correlated with energy intake $(r=0.075 ; P=0.04)$. In contrast, total IGFBP-3 levels were positively correlated with WHR $(r=0.115 ; P=0.002)$, parity $\left(r_{s}\right.$ $=0.089 ; P=0.02)$, body mass index (BMI) $(r=0.115 ; P=$ $0.002)$, physical activity $(r=0.118 ; P=0.002)$, and IGF-I levels $(r=0.588 ; P<0.0001)$ and negatively correlated with percent or absolute breast density $(r=-0.095 ; P=0.01$ and $r=-0.075$; $P=0.04$, respectively).

Conclusion Our data show that associations of some breast cancer risk factors with intact levels of IGFBP-3 are different from those with total (intact and fragmented) IGFBP-3 levels. These findings suggest that different molecular forms of IGFBP3 may bear different relations to premenopausal breast cancer risk.

\section{Introduction}

Members of the insulin-like growth factor (IGF) family have been suggested to play a role in the occurrence of cancer at various sites, including the breast [1]. In particular, laboratory studies showed that IGF-I is able to exert mitogenic and antiapoptotic effects on normal and abnormal breast cells [2]. These results are consistent with the systematic reviews reporting that higher levels of IGF-I are associated with an

$\mathrm{BMI}=$ body mass index; IGF = insulin-like growth factor; IGFBP-3 = insulin-like growth factor-binding protein-3; MET, metabolic equivalent; OR = odds ratio; $\mathrm{WHR}=$ waist-to-hip ratio. 
increased breast cancer risk among premenopausal women (reviewed in [3]).

In contrast, associations of levels of total (intact and fragmented) IGF-binding protein-3 (IGFBP-3), the main binding protein of circulating IGF-I, with risk of breast cancer are conflicting and range from a protective association in some studies to an elevated risk in others (reviewed in [3]). Similarly, several studies have examined the association of breast cancer risk factors, such as personal characteristics, including lifestyle factors, and mammographic breast density, with total IGFBP-3 levels and found inconsistent results [4-13].

At the cellular level, IGFBP-3 has been found to either suppress or enhance the action of IGF-I and these effects are regulated, at least in part, by the presence of IGFBP proteases [14]. As a result, it has been proposed that the divergence in risk estimates among studies could be due to the predominant circulating forms of IGFBP-3 (intact versus fragmented) that have been measured. This notion was examined by Rinaldi and colleagues [15] in a population of young women, and their results suggested that high levels of functional IGFBP-3, which are composed of intact IGFBP-3 and some fragments of IGFBP-3, could be associated with a reduction of breast cancer risk (odds ratio $[O R]=0.54$ ) whereas high levels of total IGFBP-3 could be associated with an increased risk of breast cancer $(O R=1.47)$. Thus, the variation in intact/functional versus total IGFBP-3 levels among subjects may differently modulate the risk of breast cancer.

The aim of this study was to examine whether circulating levels of intact IGFBP-3 and total IGFBP-3 were differently associated with several breast cancer risk factors, including mammographic breast density, a strong and independent breast cancer risk indicator [16]. To our knowledge, no other study has examined these associations with different molecular forms of IGFBP-3.

\section{Materials and methods Study population and recruitment procedures}

Details of the study design and methods have been published elsewhere [6]. Briefly, the study subjects for the present analysis were premenopausal women who received a screening mammogram between February and December 2001 at the Clinique radiologique Audet (Québec, OC, Canada). The study focused only on premenopausal women because in previous analyses of our data the associations of total IGF-I and IGFBP-3 levels with breast density were observed only among these women [6]. Women were considered premenopausal if they had at least one natural menstrual cycle within 12 months or were younger than 48 years old (if a nonsmoker) or 46 years old (if a smoker) after hysterectomy without bilateral oophorectomy [17]. Exclusion criteria included the following: diabetes mellitus; dwarfism/acromegaly; thyroid, adrenal or hepatic disease; pregnancy; use of hormonal derivatives in the last 3 months before mammography; ever use of tamoxifen or raloxifene; personal history of cancer; or breast surgery.

A total of 787 premenopausal women were found to be eligible. Among these women, 2 declined participation, 2 could not provide film mammograms, and 10 had incomplete answers for some breast cancer risk factors. In the remaining 773 women, 36 did not give authorization for blood banking of samples for further study. Therefore, a total of 737 women were included in the present analysis. This study was reviewed and approved by the research ethics committee of the Centre hospitalier affilié universitaire de Québec.

\section{Data collection}

At the radiology clinic, a trained nurse measured the women's weight (kilograms), height (centimetres), and waist and hip circumferences (centimetres) and collected $20 \mathrm{~mL}$ of blood. Known or suspected breast cancer risk factors were documented by a telephone interview and included reproductive and menstrual history, family history of breast cancer, personal history of breast biopsies, past use of contraceptives and hormone replacement therapy, smoking status, alcohol intake, education, and physical activity. The levels of physical activity in metabolic equivalent-hours per week were assessed using the validated and reproducible Nurses' Health Study II Activity and Inactivity Questionnaire [18]. Finally, each woman completed a validated [19] and self-administered semiquantitative food frequency questionnaire (97GP copyrighted at Harvard University, Boston, MA, USA). Food intake data obtained through the questionnaire were translated into nutrient intake, including energy intake (kilocalories per day), at the Channing Laboratory of Harvard University.

All mammograms were scanned at $260 \mu \mathrm{m} /$ pixel with a Kodak Lumiscan85 digitizer (Eastman Kodak Company, Rochester, NY, USA). Then, for each woman, the proportion of the breast showing tissue density (percent density in percentage) and the absolute amount of dense tissue (absolute density in square centimetres) were assessed by one trained author (CD) from the craniocaudal view of a randomly chosen breast. This assessment was performed using a computer-assisted method without any information on the women [20]. Variability in the assessment of breast density was as follows: the withinbatch intraclass correlation coefficients $(n=210$ duplicate images) were 0.98 and 0.98 and the between-batch coefficients of variation ( $n=10$ images repeated 21 times) were $4 \%$ and $5 \%$ for percent and absolute breast density measurements, respectively.

At the time of blood collection, blood constituents were rapidly aliquoted and stored at $-80^{\circ} \mathrm{C}$ until analysis. Under the supervision of one of us (MP), plasma levels of total IGF-I, total IGFBP-3, and intact IGFBP-3 ( $\mathrm{ng} / \mathrm{mL})$ were blindly assayed by enzyme-linked immunosorbent assay with reagents from Diagnostic Systems Laboratories (Webster, TX, USA). Detailed 
methods have been published elsewhere [21]. In the present study, a proxy of fragmented IGFBP-3 levels was obtained by subtracting intact IGFBP-3 levels from the total levels of IGFBP-3. These calculated levels of fragmented IGFBP-3 are based on the assumptions that (a) the assay used to measure total IGFBP-3 captures all IGFBP-3 fragments, including the intact form, and (b) the assay used to measure intact IGFBP3 captures all intact IGFBP-3. The intra-batch coefficients of variation (4 samples per batch of 39 samples for a total of 46 batches) were $10.5 \%$ and $13.2 \%$ and the between-batch coefficients of variation were $7.9 \%$ and $10.5 \%$ for total IGF-I and total IGFBP-3, respectively [6]. The intra- and betweenbatch coefficients of variation (4 samples per batch of 39 samples for a total of 22 batches) were $8.2 \%$ and $9.4 \%$, respectively, for intact IGFBP-3.

\section{Statistical methods}

Associations of breast cancer risk factors with continuous levels of intact, fragmented, and total IGFBP-3 were evaluated with the Spearman or Pearson correlation coefficients whether factors were treated as dichotomous or continuous variables, respectively. Multivariate-adjusted mean IGFBP-3 levels were assessed according to categories of variables (usually quartiles) using generalized linear models. The same approach was used to obtain mean mammographic breast density by quartiles of IGFBP-3 levels. However, absolute breast density was square-root-transformed to normalize its skewed distribution, and means are presented as back-transformed values. All statistical analyses were carried out using the SAS software system (SAS Institute Inc., Cary, NC, USA). Statistical significance was based on two-sided $P$ values.

\section{Results}

Characteristics of premenopausal women are described in Table 1. The mean value \pm standard deviation for intact IGFBP-3 levels $(1,044 \pm 234 \mathrm{mg} / \mathrm{mL})$ was clearly lower than that of total IGFBP-3 levels $(4,806 \pm 910 \mathrm{mg} / \mathrm{mL})$. The Pearson correlations of intact IGFBP-3 levels with fragmented and total IGFBP-3 levels were in the opposite direction $(r=-0.119$; $P=0.001$ and $r=0.139 ; P=0.0002$, respectively). The correlation between levels of fragmented and total IGFBP-3 was very high $(r=0.967 ; P<0.0001)$.

The multivariate-adjusted correlation of women's characteristics with IGFBP-3 levels varied according to the molecular form of the protein (Table 2). Levels of intact IGFBP-3 were negatively correlated with waist-to-hip ratio (WHR) $(r=$ $0.128 ; P=0.0005)$, alcohol intake $(r=-0.137 ; P=0.0002)$, and parity $\left(r_{s}=-0.078 ; P=0.04\right)$ and positively correlated with energy intake $(r=0.075 ; P=0.04)$; no correlation was observed with body mass index (BMI), physical activity, and IGF-I levels. In contrast, fragmented and total IGFBP-3 levels were both positively correlated with $\mathrm{BMI}(r=0.124 ; P=$ 0.0008 and $r=0.115 ; P=0.002)$, WHR $(r=0.156 ; P<$ 0.0001 and $r=0.115 ; P=0.002)$, physical activity $(r=0.097$;
Table 1

Description of the study population $(n=737)$

Mean \pm SD or Percentage

\begin{tabular}{lc}
\hline Growth factors & \\
Total IGF-I, ng/mL & $224.0 \pm 63.7$ \\
Intact IGFBP-3, ng/mL & $1,044 \pm 234$ \\
Fragmented IGFBP-3, ng/mL & $3,762 \pm 908$ \\
Total IGFBP-3, ng/mL & $4,806 \pm 910$ \\
Characteristics & \\
Age at mammography, years & $46.8 \pm 4.6$ \\
Body mass index, kg/m² & $25.2 \pm 4.5$ \\
Waist-to-hip ratio & $0.78 \pm 0.06$ \\
Alcohol intake, drinks/week & $3.4 \pm 3.8$ \\
Energy intake, kilocalories/day & $1,905 \pm 514$ \\
Physical activity, MET-hours/week & $27.2 \pm 22.2$ \\
Parity, parous percentage & 75.9 \\
Smoking, current percentage & 14.9 \\
Mammographic breast density & \\
Percent density, percentage & $42.4 \pm 24.4$ \\
Absolute density, cm² & $47.0 \pm 28.8$
\end{tabular}

IGF, insulin-like growth factor; IGFBP-3, insulin-like growth factorbinding protein-3; MET, metabolic equivalent; SD, standard deviation.

$P=0.009$ and $\mathrm{r}=0.118 ; P=0.002)$, parity $\left(\mathrm{r}_{\mathrm{s}}=0.110 ; P=\right.$ 0.003 and $\left.r_{\mathrm{s}}=0.089 ; P=0.02\right)$, and IGF-I levels $(r=0.588$; $P<0.0001$ and $r=0.588 ; P<0.0001)$. Moreover, fragmented IGFBP-3 levels were positively correlated with alcohol intake and negatively correlated with energy intake. Finally, intact, fragmented, or total IGFBP-3 levels were all positively correlated with age and negatively correlated with smoking (although the correlation was not statistically significant for smoking with intact IGFBP-3 levels, $P=0.09$ ).

Weight, waist circumference, and hip circumference were negatively correlated with intact IGFBP-3 levels and positively correlated with fragmented and total IGFBP-3 levels after adjustment for age, alcohol and energy intakes, physical activity, parity, smoking, and IGF-I levels. These correlations were statistically significant, except for the one between intact IGFBP-3 levels and hip circumference (data not shown).

No association of age at menarche, number of full-term pregnancies, age at first full-term pregnancy, lactation, family history of breast cancer, number of breast biopsies, education, past use of oral contraceptives, past use of hormone replacement therapy, or height was observed with intact, fragmented, and total IGFBP-3 levels (data not shown). Moreover, all variables found to be correlated with intact, fragmented, or total 
Table 2

Means and correlations of IGFBP-3 levels with IGF-I levels and women's characteristics

\begin{tabular}{|c|c|c|c|c|}
\hline & \multirow[b]{2}{*}{ Number } & \multicolumn{3}{|c|}{ Adjusted means of IGFBP-3 levelsa } \\
\hline & & Intact, ng/mL & Fragmented, ng/mL & Total, ng/mL \\
\hline \multicolumn{5}{|l|}{ Total IGF-I, ng/mL } \\
\hline$\leq 179.6$ & 185 & 1,051 & 3,081 & 4,132 \\
\hline $179.7-218.1$ & 184 & 1,040 & 3,587 & 4,627 \\
\hline $218.2-260.7$ & 184 & 1,033 & 3,935 & 4,968 \\
\hline$>260.7$ & 184 & 1,051 & 4,451 & 5,502 \\
\hline $\mathrm{rb}^{\mathrm{b}}(P)$ & & $0.010(0.78)$ & $0.554(<0.0001)$ & $0.555(<0.0001)$ \\
\hline $\mathrm{r}^{\mathrm{b}}(P)^{\mathrm{a}}$ & & $0.023(0.53)$ & $0.588(<0.0001)$ & $0.588(<0.0001)$ \\
\hline \multicolumn{5}{|c|}{ Age at mammography, years } \\
\hline$\leq 44$ & 221 & 1,007 & 3,673 & 4,680 \\
\hline $45-47$ & 168 & 1,025 & 3,746 & 4,770 \\
\hline $48-50$ & 200 & 1,062 & 3,821 & 4,883 \\
\hline$>50$ & 148 & 1,096 & 3,835 & 4,931 \\
\hline $\mathrm{r}^{\mathrm{b}}(P)$ & & $0.083(0.02)$ & $0.028(0.46)$ & $0.049(0.19)$ \\
\hline $\mathrm{r}^{\mathrm{b}}(P)^{\mathrm{a}}$ & & $0.113(0.002)$ & $0.104(0.005)$ & $0.139(0.0002)$ \\
\hline \multicolumn{5}{|c|}{ Body mass index, $\mathrm{kg} / \mathrm{m}^{2}$} \\
\hline$\leq 22.0$ & 186 & 1,071 & 3,680 & 4,750 \\
\hline $22.1-24.4$ & 187 & 1,057 & 3,671 & 4,728 \\
\hline $24.5-27.4$ & 183 & 1,003 & 3,771 & 4,775 \\
\hline$>27.4$ & 181 & 1,044 & 3,932 & 4,976 \\
\hline $\mathrm{rb}^{\mathrm{b}}(P)$ & & $-0.070(0.06)$ & $0.153(<0.0001)$ & $0.134(0.0003)$ \\
\hline $\mathrm{r}^{\mathrm{b}}(P)^{\mathrm{a}}$ & & $-0.024(0.52)$ & $0.124(0.0008)$ & $0.115(0.002)$ \\
\hline \multicolumn{5}{|l|}{ Waist-to-hip ratio } \\
\hline$\leq 0.740$ & 184 & 1,106 & 3,620 & 4,726 \\
\hline $0.741-0.780$ & 196 & 1,062 & 3,708 & 4,770 \\
\hline $0.781-0.820$ & 185 & 987 & 3,685 & 4,671 \\
\hline$>0.820$ & 172 & 1,017 & 4,061 & 5,078 \\
\hline $\mathrm{rb}^{\mathrm{b}}(P)$ & & $-0.139(0.0001)$ & $0.188(<0.0001)$ & $0.152(<0.0001)$ \\
\hline $\mathrm{r}^{\mathrm{b}}(P)^{\mathrm{a}}$ & & $-0.128(0.0005)$ & $0.156(<0.0001)$ & $0.115(0.002)$ \\
\hline
\end{tabular}

Alcohol intake, drinks/week 
Table 2 (Continued)

\begin{tabular}{|c|c|c|c|c|}
\hline Non-drinkers & 53 & 1,080 & 3,691 & 4,771 \\
\hline$\leq 1.0$ & 234 & 1,066 & 3,716 & 4,781 \\
\hline $1.1-4.0$ & 238 & 1,063 & 3,734 & 4,797 \\
\hline$>4.0$ & 212 & 989 & 3,864 & 4,853 \\
\hline $\mathrm{rb}^{\mathrm{b}}(P)$ & & $-0.113(0.002)$ & $0.002(0.96)$ & $-0.027(0.46)$ \\
\hline $\mathrm{rb}^{\mathrm{b}}(P)^{\mathrm{a}}$ & & $-0.137(0.0002)$ & $0.079(0.03)$ & $0.035(0.34)$ \\
\hline \multicolumn{5}{|c|}{ Energy intake, kilocalories/day } \\
\hline$\leq 1,564.21$ & 185 & 1,023 & 3,807 & 4,830 \\
\hline $1,564.22-1,855.02$ & 184 & 1,040 & 3,837 & 4,878 \\
\hline $1,855.03-2,199.36$ & 184 & 1,031 & 3,756 & 4,787 \\
\hline$>2,199.36$ & 184 & 1,081 & 3,649 & 4,730 \\
\hline $\mathrm{rb}^{\mathrm{b}}(P)$ & & $0.058(0.12)$ & $-0.004(0.92)$ & $0.011(0.76)$ \\
\hline $\mathrm{r}^{\mathrm{b}}(P)^{\mathrm{a}}$ & & $0.075(0.04)$ & $-0.080(0.03)$ & $-0.055(0.14)$ \\
\hline \multicolumn{5}{|c|}{ Physical activity, MET-hours/week } \\
\hline$\leq 10.79$ & 185 & 1,036 & 3,647 & 4,683 \\
\hline $10.80-22.27$ & 184 & 1,052 & 3,737 & 4,789 \\
\hline $22.28-36.64$ & 184 & 1,033 & 3,783 & 4,815 \\
\hline$>36.64$ & 184 & 1,055 & 3,884 & 4,939 \\
\hline $\mathrm{rb}^{\mathrm{b}}(P)$ & & $0.077(0.04)$ & $0.031(0.40)$ & $0.050(0.17)$ \\
\hline $\mathrm{r}^{\mathrm{b}}(P)^{\mathrm{a}}$ & & $0.069(0.06)$ & $0.097(0.009)$ & $0.118(0.002)$ \\
\hline \multicolumn{5}{|l|}{ Parity } \\
\hline Nulliparous & 178 & 1,079 & 3,616 & 4,695 \\
\hline Parous & 559 & 1,033 & 3,809 & 4,842 \\
\hline$r_{s}^{c}(P)$ & & $-0.063(0.09)$ & $0.135(0.0002)$ & $0.121(0.001)$ \\
\hline $\mathrm{r}_{\mathrm{s}}{ }^{\mathrm{c}}(P)^{\mathrm{a}}$ & & $-0.078(0.04)$ & $0.110(0.003)$ & $0.089(0.02)$ \\
\hline \multicolumn{5}{|l|}{ Smoking status } \\
\hline None/ex-smoker & 627 & 1,048 & 3,791 & 4,839 \\
\hline Current & 110 & 1,020 & 3,598 & 4,618 \\
\hline$r_{s}^{c}(P)$ & & $-0.094(0.01)$ & $-0.117(0.001)$ & $-0.129(0.0004)$ \\
\hline $\mathrm{r}_{\mathrm{s}}{ }^{\mathrm{c}}(P)^{\mathrm{a}}$ & & $-0.063(0.09)$ & $-0.090(0.01)$ & $-0.091(0.01)$ \\
\hline
\end{tabular}

aMeans and correlations are adjusted for variables in the table. bPearson correlation ( $r$ ) between continuous variables; adjusted correlations are partial Pearson coefficients. cSpearman correlation $\left(r_{s}\right)$ between dichotomous factor and continuous levels of IGFBP-3; adjusted correlations are partial Spearman coefficients. IGF, insulin-like growth factor; IGFBP-3, insulin-like growth factor-binding protein-3; MET, metabolic equivalent. 
IGFBP-3 levels remained statistically significant with comparable correlations after further adjustment for those factors (data not shown).

Table 3 shows correlations of mammographic breast density with intact, fragmented, and total IGFBP-3 levels. In unadjusted models, we found that intact IGFBP-3 levels were positively associated with percent breast density (mean percent breast density $=40.6,41.6,41.5$, and 45.7; $r=0.075 ; P=$ 0.04 ) whereas fragmented (mean percent breast density $=$ $47.1,44.5,40.4$, and $37.4 \% ; r=-0.171 ; P<0.0001)$ and total (mean percent breast density $=46.3,45.6,39.8$, and $37.6 \% ; r=-0.151 ; P<0.0001)$ IGFBP-3 levels were negatively associated with percent breast density. Negative associations of intact (mean absolute breast density $=48.2$, 46.0, 47.0 , and $46.7 \mathrm{~cm}^{2} ; \mathrm{r}=-0.010 ; P=0.79$ ), fragmented (mean absolute breast density $=49.3,48.3,46.6$, and $43.7 \mathrm{~cm}^{2} ; \mathrm{r}=$ $-0.092 ; P=0.01$ ), and total (mean absolute breast density $=$ $50.2,49.4,45.0$, and $43.3 \mathrm{~cm}^{2} ; \mathrm{r}=-0.094 ; P=0.01$ ) IGFBP3 levels with absolute breast density were observed before adjusting for confounders, although the association between intact IGFBP-3 levels and absolute breast density did not reach statistical significance. After adjustment for factors included in Table 1, fragmented and total IGFBP-3 levels were negatively correlated with percent $(r=-0.105 ; P=0.004$ and $r=-0.095 ; P=0.01)$ and absolute $(r=-0.066 ; P=0.07$ and $r=-0.075 ; P=0.04)$ breast density whereas levels of intact IGFBP-3 were not significantly correlated with either percent or absolute breast density. After further adjustment for age at menarche, number of full-term pregnancies, age at first fullterm pregnancy, lactation, family history of breast cancer, number of breast biopsies, education, past use of oral contra- ceptives, past use of hormone replacement therapy, and height, these correlations were all slightly stronger, and the borderline negative correlation between absolute density and fragmented IGFBP-3 levels became statistically significant.

\section{Discussion}

Our data suggest that, among premenopausal women, the associations of some breast cancer risk factors with intact levels of IGFBP-3 are different from those with total (intact and fragmented) IGFBP-3 levels. Our data show that lower WHR, lower alcohol intake, and higher energy intake or nulliparity are associated with higher levels of intact IGFBP-3 whereas associations in the opposite direction are observed between these breast cancer risk factors and fragmented or total IGFBP-3 levels. Moreover, fragmented or total IGFBP-3 levels were negatively associated with mammographic breast density, one of the strongest known breast cancer risk factors, whereas no such association was seen with intact IGFBP-3. These findings suggest that different forms of IGFBP-3 may bear different relations to premenopausal breast cancer risk.

This is the first epidemiologic study to examine the association of intact and total IGFBP-3 measurements with a large set of breast cancer risk factors, including mammographic breast density. So far, two studies have reported on the association of different measurements of IGFBP-3 levels with the risk of breast cancer and found inconsistent results [15,22]. The first case-control study of 40 cases and 40 age- and race-matched controls among premenopausal and postmenopausal women failed to show any association of intact, fragmented, or total IGFBP-3 levels with the risk of breast cancer [22]. In contrast, recent data from the New York University Women's Health

Table 3

Means and correlations of IGFBP-3 levels with mammographic breast density

\begin{tabular}{|c|c|c|c|c|c|c|}
\hline \multirow[b]{2}{*}{ Levels of IGFBP-3 } & \multicolumn{3}{|c|}{ Adjusted means of percent density (percentage)a } & \multicolumn{3}{|c|}{ Adjusted means of absolute density $\left(\mathrm{cm}^{2}\right)^{a, b}$} \\
\hline & Intact ${ }^{c}$ & Fragmented & Totale & Intactc & Fragmented & Totale \\
\hline Quartile $1(n=185)$ & 42.2 & 45.3 & 44.5 & 48.6 & 48.3 & 49.4 \\
\hline Quartile $2(n=184)$ & 42.9 & 44.3 & 44.7 & 46.3 & 48.0 & 48.6 \\
\hline Quartile $3(n=184)$ & 40.4 & 40.3 & 40.7 & 45.7 & 45.9 & 45.0 \\
\hline Quartile $4(n=184)$ & 44.0 & 39.6 & 39.6 & 45.5 & 43.9 & 43.1 \\
\hline$r^{f}(P)$ & $0.075(0.04)$ & $-0.171(<0.0001)$ & $-0.151(<0.0001)$ & $-0.010(0.79)$ & $-0.092(0.01)$ & $-0.094(0.01)$ \\
\hline $\mathrm{r}^{\mathrm{f}}(P)^{\mathrm{a}}$ & $0.031(0.40)$ & $-0.105(0.004)$ & $-0.095(0.01)$ & $-0.029(0.43)$ & $-0.066(0.07)$ & $-0.075(0.04)$ \\
\hline $\mathrm{r}^{\mathrm{f}}(P) \mathrm{g}$ & $0.022(0.55)$ & $-0.112(0.003)$ & $-0.104(0.005)$ & $-0.042(0.26)$ & $-0.078(0.04)$ & $-0.090(0.02)$ \\
\hline
\end{tabular}

aMeans and correlations are adjusted for age, body mass index, waist-to-hip ratio, alcohol intake, energy intake, physical activity, parity, smoking status, and total IGF-I levels. bMeans of absolute density are presented as back-transformed values; square-root-transformed absolute density is used in the correlation. " Quartiles of intact IGFBP-3 are $\leq 883.80,883.81$ to $1,021.00,1,021.01$ to $1,170.50$, and $>1,170.50 \mathrm{ng} / \mathrm{mL}$. dQuartiles of fragmented IGFBP-3 are $\leq 3,137.50,3,137.51$ to $3,662.50,3,662.51$ to $4,263.00$, and $>4,263.00 \mathrm{ng} / \mathrm{mL}$. eQuartiles of total IGFBP-3 are $\leq 4,183.0,4,183.1$ to $4,695.0,4,695.1$ to $5,290.0$, and $>5,290.0 \mathrm{ng} / \mathrm{mL}$. fPearson correlation between continuous variables; adjusted correlations are partial Pearson coefficients. 9Correlations are adjusted for age, body mass index, waist-to-hip ratio, alcohol intake, energy intake, physical activity, parity, smoking status, total IGF-I levels, age at menarche, number of full-term pregnancies, age at first full-term pregnancy, lactation, family history of breast cancer, number of breast biopsies, education, past use of oral contraceptives, past use of hormone replacement therapy, and height. 
Study suggested that, among young women, high levels of functional IGFBP-3 could be associated with a reduction of breast cancer risk whereas high levels of total IGFBP-3 could be associated with an increased risk of breast cancer [15].

Mammographic breast density is a strong biomarker for breast cancer [16]. Contrary to our expectations, the associations of intact and total IGFBP-3 levels with breast density do not seem to mirror the IGFBP-3-breast cancer associations in the study of Rinaldi and colleagues [15]. However, both studies differ on several points regardless of the breast density/risk issue. In the study of Rinaldi and colleagues, women were younger and leaner and more were nulliparous and they had different mean levels of growth factors. Most importantly, the measurement of functional IGFBP-3 concentrations was assessed by ligand immunofunctional assay, which measured the forms of IGFBP-3 that are able to bind the IGF ligand. It has been shown that different lengths of IGFBP-3 fragments, including the first 97 residues (1-97/GFBP-3), are capable of binding IGFs, though with a lower affinity than intact IGFBP-3 $[14,23]$. In the present study, these $1-97$ IGFBP-3 fragments are not detected by the assay used [21] and, thus, such fragments are not contributing to our intact IGFBP-3 measurement. This difference between assays may explain, at least in part, the higher correlation between functional and total IGFBP-3 levels $(r=0.45)$ in the study of Rinaldi and colleagues.

Meanwhile, laboratory studies showed that different molecular forms of IGFBP-3 such as intact IGFBP-3, 1-160IGFBP-3, and 1-95IGFBP-3 fragments have different proliferative and apoptotic activities on cells $[24,25]$. It has been observed that, at the same concentration, $1-160$ lGFBP-3 fragments stimulate proliferation whereas ${ }^{1-95}$ IGFBP-3 fragments inhibit proliferation of prostate carcinoma cells [24]. Moreover, 1-95IGFBP-3 fragments were shown to induce morphological changes and apoptosis of breast carcinoma cells [25]. The 1-95/GFBP-3 fragments were suggested to inhibit, at least in part, the mitogenic signals resulting from IGF-I receptor activation $[23,24,26,27]$. These findings suggest that the proportions of 1-95IGFBP-3, 1-160IGFBP-3, and 1-264IGFBP-3 (intact IGFBP-

3) relative to total IGFBP-3 are important, and methods should be developed to precisely measure each of these fragments since they may have different effects on target cells. Therefore, differences in the assay and the molecular forms of IGFBP-3 measurement may explain, to some extent, the inconsistency between the study of Rinaldi and colleagues [15] and the present study and the heterogeneity between studies evaluating total IGFBP-3 levels with the risk of breast cancer or its associated risk factors [3-13].

The major strengths of this study include the reliability of breast density measurements, the extensive information on breast cancer risk factors, and the relatively large sample size. However, this study also has some limitations. First, levels of fragmented IGFBP-3 were not assayed but derived from the difference between levels of total and intact IGFBP-3. This difference can be considered only as a proxy of all IGFBP-3 fragments. Therefore, associations observed with estimated fragmented IGFBP-3 levels have to be interpreted with caution. Nevertheless, since the association of several breast cancer risk factors with estimated fragmented IGFBP-3 was quite different from their association with intact IGFBP-3, our results suggest that further studies should measure levels of fragmented IGFBP-3 using specific assays and should examine intact and fragmented IGFBP-3 separately. It has been proposed that long-term storage may increase proteolytic activity and, therefore, increase levels of fragmented IGFBP-3 [28]. However, our results were essentially unchanged after further adjustment for the length of storage in the analysis. Second, laboratory measurements were performed on non-fasting blood samples. In a recent study, it has been suggested that fasting and fed state can affect levels of IGF-I and IGFBP-3 [29]. However, our results remain similar when models were further adjusted for the number of hours since the last meal. Third, blood collection was not timed with a specific phase of the menstrual cycle. However, the phase of cycle at the time of blood collection was associated with neither IGFBP-3 levels nor breast density. Moreover, further adjustment for menstrual cycle phase at the time of blood collection (and mammogram) had essentially no confounding effect in these data. Fourth, because an exploratory approach was used and multiple testing was carried out, we cannot totally exclude the possibility that some of the findings could be due to chance. Moreover, some of the observed correlations are weak with uncertain clinical significance. Therefore, these data need to be confirmed by other studies. Finally, the cross-sectional design of the study does not allow us to determine the temporality of the relation between IGFBP-3 levels and breast cancer risk factors.

\section{Conclusion}

The associations of several breast cancer risk factors with IGFBP-3 levels vary in strength and even direction depending on the molecular form of IGFBP-3. These results suggest that different molecular forms of circulating IGFBP-3 (intact versus fragmented) may bear different relations to the risk of breast cancer and, possibly, of cancer at other sites. Further studies measuring intact, fragmented, and total IGFBP-3 would help to identify whether this molecule is a cancer risk factor, a preventive factor, or both.

\section{Competing interests}

The authors declare that they have no competing interests.

\section{Authors' contributions}

CD was involved in the study design, data collection, mammographic breast density assessments, statistical analysis, and drafting of the manuscript. JB and SB were involved in the study design, data collection and statistical analysis. MP was 
involved in the study design and performed the growth factor analyses. All authors contributed to revisions of the manuscript and read and approved the final manuscript.

\section{Acknowledgements}

We thank the Clinique radiologique Audet for their excellent collaboration and all participating women for their contribution. This study was supported by a grant from the Translation Acceleration Grants Program for Breast Cancer Control of the Canadian Breast Cancer Research Alliance and the Canadian Institutes of Health Research. CD was supported by post-doctoral fellowships from The Cancer Research Society Inc., and the Canadian Institutes of Health Research.

\section{References}

1. $Y u H$, Rohan $T$ : Role of the insulin-like growth factor family in cancer development and progression. J Natl Cancer Inst 2000, 92:1472-1489.

2. Pollak MN: Endocrine effects of IGF-I on normal and transformed breast epithelial cells: potential relevance to strategies for breast cancer treatment and prevention. Breast Cancer Res Treat 1998, 47:209-217.

3. Renehan AG, Harvie $M$, Howell $A$ : Insulin-like growth factor (IGF)-I, IGF binding protein-3, and breast cancer risk: eight years on. Endocr Relat Cancer 2006, 13:273-278.

4. Allen NE, Appleby PN, Kaaks R, Rinaldi S, Davey GK, Key TJ: Lifestyle determinants of serum insulin-like growth-factor-I (IGFI), C-peptide and hormone binding protein levels in British women. Cancer Causes Contro/ 2003, 14:65-74.

5. Boyd NF, Stone J, Martin LJ, Jong R, Fishell E, Yaffe M, Hammond G, Minkin S: The association of breast mitogens with mammographic densities. Br J Cancer 2002, 87:876-882.

6. Diorio C, Pollak M, Byrne C, Masse B, Hebert-Croteau N, Yaffe M, Cote G, Berube S, Morin C, Brisson J: Insulin-like growth factorI, IGF-binding protein-3, and mammographic breast density. Cancer Epidemiol Biomarkers Prev 2005, 14:1065-1073.

7. Gram IT, Norat T, Rinaldi S, Dossus L, Lukanova A, Téhard B, Clavel-Chapelon F, van Gils $\mathrm{CH}$, van Noord PA, Peeters $\mathrm{PH}$, Bueno-de-Mesquita HB, Nagel G, Linseisen J, Lahmann PH, Boeing $\mathrm{H}$, Palli D, Sacerdote C, Panico S, Tumino R, Sieri S, Dorronsoro M, Quirós JR, Navarro CA, Barricarte A, Tormo MJ, González CA, Overvad K, Paaske Johnsen S, Olsen A, Tjønneland A, et al:: Body mass index, waist circumference and waist-hip ratio and serum levels of IGF-I and IGFBP-3 in European women. Int $J$ Obes (Lond) 2006, 30:1623-1631.

8. Holmes MD, Pollak MN, Hankinson SE: Lifestyle correlates of plasma insulin-like growth factor I and insulin-like growth factor binding protein 3 concentrations. Cancer Epidemiol Biomarkers Prev 2002, 11:862-867.

9. Jernstrom H, Deal C, Wilkin F, Chu W, Tao Y, Majeed N, Hudson T, Narod SA, Pollak M: Genetic and nongenetic factors associated with variation of plasma levels of insulin-like growth factor-I and insulin-like growth factor-binding protein-3 in healthy premenopausal women. Cancer Epidemiol Biomarkers Prev 2001, 10:377-384.

10. Lukanova A, Toniolo P, Akhmedkhanov A, Hunt K, Rinaldi S, Zeleniuch-Jacquotte A, Haley NJ, Riboli E, Stattin P, Lundin E, Kaaks R: A cross-sectional study of IGF-I determinants in women. Eur J Cancer Prev 2001, 10:443-452.

11. Morimoto LM, Newcomb PA, White E, Bigler J, Potter JD: Variation in plasma insulin-like growth factor-1 and insulin-like growth factor binding protein-3: personal and lifestyle factors (United States). Cancer Causes Control 2005, 16:917-927.

12. Slattery ML, Baumgartner KB, Byers T, Guiliano A, Sweeney $C$, Herrick J, Curtin K, Murtaugh M, Wolff R: Genetic, anthropometric, and lifestyle factors associated with IGF-1 and IGFBP-3 levels in Hispanic and non-Hispanic white women. Cancer Causes Control 2005, 16:1147-1157.

13. Voskuil DW, de Mesquita HB, Kaaks R, van Noord PA, Rinaldi S, Riboli E, Grobbee DE, Peeters PH: Determinants of circulating insulin-like growth factor (IGF)-I and IGF binding proteins 1-3 in premenopausal women: physical activity and anthropometry (Netherlands). Cancer Causes Control 2001, 12:951-958.
14. Firth SM, Baxter RC: Cellular actions of the insulin-like growth factor binding proteins. Endocr Rev 2002, 23:824-854.

15. Rinaldi S, Kaaks R, Zeleniuch-Jacquotte A, Arslan AA, Shore RE, Koenig KL, Dossus L, Riboli E, Stattin P, Lukanova A, Toniolo P. Insulin-like growth factor-I, IGF binding protein-3, and breast cancer in young women: a comparison of risk estimates using different peptide assays. Cancer Epidemiol Biomarkers Prev 2005, 14:48-52.

16. Boyd NF, Rommens JM, Vogt K, Lee V, Hopper JL, Yaffe MJ, Paterson AD: Mammographic breast density as an intermediate phenotype for breast cancer. Lancet Oncol 2005, 6:798-808.

17. London SJ, Colditz GA, Stampfer MJ, Willett WC, Rosner B Speizer FE: Prospective study of relative weight, height, and risk of breast cancer. J Am Med Assoc 1989, 262:2853-2858.

18. Wolf AM, Hunter DJ, Colditz GA, Manson JE, Stampfer MJ, Corsano KA, Rosner B, Kriska A, Willett WC: Reproducibility and validity of a self-administered physical activity questionnaire. Int J Epidemiol 1994, 23:991-999.

19. Caan BJ, Slattery ML, Potter J, Quesenberry CP, Coates AO, Schaffer DM: Comparison of the Block and the Willett selfadministered semiquantitative food frequency questionnaires with an interviewer-administered dietary history. Am J Epidemiol 1998, 148:1137-1147.

20. Boyd NF, Byng JW, Jong RA, Fishell EK, Little LE, Miller AB, Lockwood GA, Tritchler DL, Yaffe MJ: Quantitative classification of mammographic densities and breast cancer risk: results from the Canadian National Breast Screening Study. J Natl Cancer Inst 1995, 87:670-675.

21. Diamandi A, Mistry J, Krishna RG, Khosravi J: Immunoassay of insulin-like growth factor-binding protein-3 (IGFBP-3): new means to quantifying IGFBP-3 proteolysis. I Clin Endocrinol Metab 2000, 85:2327-2333.

22. Li BD, Khosravi MJ, Berkel HJ, Diamandi A, Dayton MA, Smith M, Yu H: Free insulin-like growth factor-I and breast cancer risk. Int J Cancer 2001, 91:736-739.

23. Devi GR, Yang DH, Rosenfeld RG, Oh Y: Differential effects of insulin-like growth factor (IGF)-binding protein-3 and its proteolytic fragments on ligand binding, cell surface association, and IGF-I receptor signaling. Endocrinology 2000, 141:4171-4179.

24. Angelloz-Nicoud P, Lalou C, Binoux M: Prostate carcinoma (PC3) cell proliferation is stimulated by the $22-25-\mathrm{kDa}$ proteolytic fragment (1-160) and inhibited by the 16-kDa fragment (1-95) of recombinant human insulin-like growth factor binding protein-3. Growth Horm IGF Res 1998, 8:71-75.

25. Bernard L, Babajko S, Binoux M, Ricort JM: The amino-terminal region of insulin-like growth factor binding protein-3, (195)IGFBP-3, induces apoptosis of MCF-7 breast carcinoma cells. Biochem Biophys Res Commun 2002, 293:55-60.

26. Lalou $C$, Lassarre C, Binoux M: A proteolytic fragment of insulinlike growth factor (IGF) binding protein-3 that fails to bind IGFs inhibits the mitogenic effects of IGF-I and insulin. Endocrinology 1996, 137:3206-3212.

27. Zadeh SM, Binoux M: The 16-kDa proteolytic fragment of insulin-like growth factor (IGF) binding protein-3 inhibits the mitogenic action of fibroblast growth factor on mouse fibroblasts with a targeted disruption of the type 1 IGF receptor gene. Endocrinology 1997, 138:3069-3072.

28. Khosravi J, Diamandi A, Bodani U, Khaja N, Krishna RG: Pitfalls of immunoassay and sample for IGF-I: comparison of different assay methodologies using various fresh and stored serum samples. Clin Biochem 2005, 38:659-666.

29. Flanagan DE, Holt RI, Owens PC, Cockington RJ, Moore VM, Robinson JS, Godsland IF, Phillips DI: Gender differences in the insulin-like growth factor axis response to a glucose load. Acta Physiol (Oxf) 2006, 187:371-378. 